\title{
TOCHARSKO-SLOVANSKÉ LEXIKÁLNÍ PARALELY - NOVÁ SROVNÁNÍ
}

\author{
TOCHARIAN-SLAVIC LEXICAL PARALLELS - NEW \\ COMPARISONS
}

\begin{abstract}
The article begins with an overview of the previous literature studying the Tocharian-(Balto-)Slavic lexical and morphological parallels was summarized. In this context three new comparisons were presented: 1. Tocharian A kuk', du. kukäm 'heel'; B kuke*, du. kukene id.? Old Church Slavonic kъkъnja 'Schienbein, Unterschenkel', plus Middle Welsh (13th cent.) kukyn, (14th cent.) kygwng/ kygwn/kygwg, Welsh cwgn, pl. cygnau, 'joint, knuckle; knot or joint on stem or root of plant; knot, knur (in wood); link in chain'; Irish cocung 'chain'; 2. Toch. B lasto 'belonging to branches of a shrub' Slavic *lîstı 'leaf', plus hypothetical Baltic *lišta(s), reconstructed on the basis of Fenno-Volgaic *lešte 'leaf'; 3. Toch. B rīye, A ri 'city' < *dreuio- East Slavic *dervınja 'village', both originally 'wooden'.
\end{abstract}

\section{KEYWORDS}

Tocharian; Slavic; Balto-Slavic; isogloss; etymology

Specifické (balto-)slovansko-tocharské izoglosy byly a jsou studovány zejména v rovině lexikální, ale nechybí ani pohled morfologický. Za posledních šest desetiletí bylo této problematice věnováno více než 25 článků či kapitol v monografích, když odhlédneme od konkrétních hesel srovnávacích či etymologických slovníků (např. AdAms 2013; Hilmarsson 1996; VAN WindeKenS 1976). Připomeňme v následujícím abecedním přehledu autory, kteří již k tomuto tématu přispěli (symbol ${ }^{\mathrm{BS}}$ odkazuje na balto-slovanskou perspektivu daných studií): BLAžEK 1991, 1994, 1995a, b, 1997, 1999, 2003, 2013 BS; BONFATE 1979 ${ }^{\text {BS }}$, 1984; ČOP 1959-60; GEORGIEV 1958 ${ }^{\text {BS }}$,

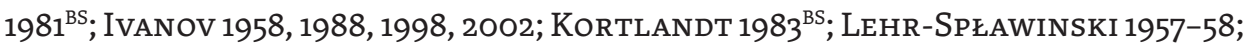




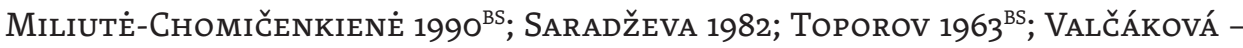
BLAŽEK 1997; VAN WindEKENS $1971^{\text {BS }}$, $1976^{\text {BS; }}$; WiTCZAK $1999^{\text {BS }}$.

Předkládaná tř̌i srovnání se dosud ve jmenovaných studiích neobjevila.

1. Toch. A kuk*, du. kukäm ,pata,' (DTA 147); B kuke*, du. kukene id.? zůstává doposud bez nadějné indoevropské etymologie (sr. ADAMS 2013, 191: 'Further connections are unknown'). Spolu s Adamsem je třeba odmítnout pokus Van Windekense (1976, 628) slovo vysvětlit jako adaptaci permského označení ,nohy * *kok, ostatně izolovaného mezi uralskými jazyky. Ještě beznadějnější paralelou je čukotské kyjä ,pata podle téhož autora. Jednak tu je obrovská geografická vzdálenost dělící historické Tochary a současné obyvatele Čukotky, především ale paralely v blízce př́ibuzných jazycích nepotvrzují př́tomnost mediální veláry, sr. čukči kajalyan, pl. kajat ,pata;,

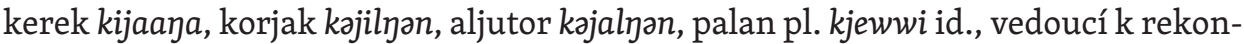
strukci čukčo-korjacké praformy *kajæ (FORTESCUE 2005, 144).

I když se ve finální slabice skrývá duálový sufix, který je tocharskou inovací, tocharská ,pata má slibné příbuzenstvo ve stsl. kъkъnja ,holeň, bérec' (KARLíková, ESJS 7, 392; sr. PoKORNY 1959, 589) a v ostrovních keltských jazycích: střvelš. (13. století) kukyn, (14. století) kygwng/kygwn/kygwg, velš. cwgn, pl. cygnau, ,kloub; článek stonku rostliny; článek v řetězu'; ir. cocung ,řetěz' (GPC).

Dodejme, že sémantický rozptyl připomíná germ. *hanha- \& *hanhila(n)- ,pata' oproti lit. kìnka f. ,noha, stehno, kolenní čéška' (KROONEN 2013, 209) nebo véd. pấrṣ-

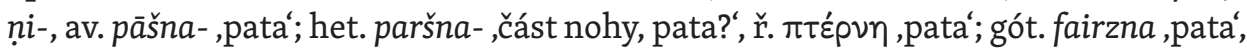
oproti toch. B porsnai ,kotník'; lat. perna ,kyčel, zadní strana stehna, stehno, horní část nohy' (AdAMS 2013, 435; KROONEN 2013, 137; AdAMs, EIEC 265).

2. Toch. B lasto m. překládá Adams $(2013,593)$ jako ,kůra kořene ('root-bark') v pasáži [ka] ravīräșsa witsako karavīräșse lasto ,kořen oleandru, lasto oleandr ' [IT/106a2 ${ }^{\mathrm{E}}$ ], týkající se léčivých ingrediencí, kde karavīra- je fytonymum označující ,oleandr (Nerium indicum) převzaté $\mathrm{z}$ buddhistického hybridního sanskrtu (BHS). Ohledně původu slova se Adams spokojuje s komentářem: 'Etymology unknown'.

Ve své recenzi Melanie Malzahn[ová] $(2016,663)$ upozorňuje na adjektivní derivát lästäșse, jenž by měl být utvořen $\mathrm{z}$ ekvivalentu slova, kterému v bhs. odpovídá gaṇ̂a- ,stéblo či stonek rostliny' ('stalk of a plant'). Odtud odvozuje, že lasto se musí vztahovat $\mathrm{k}$ větvím keře, a nikoliv $\mathrm{k}$ jeho kořenům. Vzhledem $\mathrm{k}$ tomu, že toch. B a ä může být reflexem ie. * ${ }^{i}$, toto řešení otevírá i cestu ke srovnání s psl. *lîstъ ,list' >

1 Podle Adamse $(1988,15)$ toto pravidlo platí za př́tomnosti hlásek *u či *s, např. toch. A wät, B wate ,druhý" < *duito-; B wase ,jed“ < *uiso- (AdAms 2013, 625-26, 634); sr. ale B śä- ,uvést do pohybu' \& śänāsk-

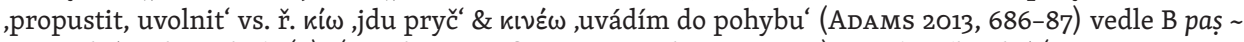
A pis ,jdi!'< ob. toch. *p(ä)- (regulérní prefix tvořící toch. imperativ) + ie. ${ }^{*} \mathrm{H}_{1} i d^{h} i$,jdi!' (AdAms 2013, 65; VAN WindeKens 1976, 21). Každopádně, pro lasto jsou podmínky platnosti změny ${ }^{*} i<a$, jak je zformuloval Adams, splněny. 
stsl. listz, bulh., mak. list, sch., sln. lîst, slk., č., h+dluž. list, plb. laist, kaš. lëst, stpol. \& pol. dial., br., r. list, ukr. lyst (JANYŠKovÁ, ESJS 7, 426); r. dial. list znamená též ,větev' (TOPOROv 1990, 39).

Finální -o v tocharském slově může být sekundární, jak uvažuje Adams (2013, 593; sr. 431: 'bewegliches -o' v petso vs. pets ,manžel'), nebo odráží singulativní *-ōn

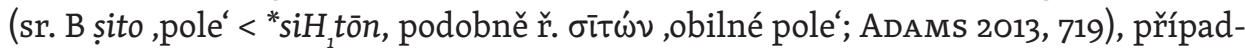
ně naopak kolektivní ${ }^{*}-\bar{a}<{ }^{*}-e H_{2}$ (sr. B lesto ,hnízdo, doupě $<{ }^{*} \log ^{h}-\mathrm{stH}_{2}-e \mathrm{H}_{2}{ }^{*}$,místo $\mathrm{k}$ ležení, podobně prus. lasto ,postel'; nebo B wasto, A wäst ,dvojmo, dvojitě $<$ *dui(s)-st $\mathrm{H}_{2} \mathrm{eH}-\mathrm{H}$, odpovídající skt. dviștha- ,stojící na dvou místech [Sūryasiddhānta], dvișțhā- ,dvojznačný, nejednoznačný" [Agni-Purāṇa] - viz AdAMs 2013, 609, 634; Pinault 2008, 450).

Slovanské formy kolísají mezi o- a u-kmeny, zatímco kořenové $i$ odráží diftong *-ei- (sr. JANYŠKovÁ, ESJS 7, 426).

Toch. AB lit- ,skonat, upadnout, pohybovat (se) 'nabízí sémantický klíč k této etymologii. Idea ,padání představuje jednu z typických charakteristik pro listí, a tedy i sémantickou motivaci, sr. skt. páttra- ,list, okvětní lístek' [KātyŚr, Mn, MBh], ale také ,ptačí křídlo, pero' [VS, ŚBr], vše od slovesa pat- ,letět' [RV], ,upadnout, padat' [Mn, MBh] (MW 580-81; EWAI I, 71, 74-75). Předložené řešení operuje s pravidlem ${ }^{*}-T+T->{ }^{*}$-st- jak ve slovanštině, tak tocharštině. Jestliže na slovanské půdě jde o jev všeobecně přijímaný, v tocharštině je situace složitější. Např. Van Windekens (1976, 105) soudil, že * $-T+T$ - > toch. -ts $(t s)$-, zatímco Adams $(1988,39)$ rozlišuje * ${ }^{*} T^{5} T y->$ -tsts-, ale *-T ${ }^{*} T>-s t-$. Vývoj vedoucí ke -st- v toch. B může být ilustrován takovým př́kladem jako B klestetstse ,ušpiněný, poskvrněný', implikujícím substantivum *kleste < *glod-to-, jemuž odpovídá niz. klatten ,poskvrnit', stsev. klessa ,skvrna od špíny', klessa ,poskvrnit' (AdAMs 2013, 247; Hilmarsson 1996, 150).

Pozn.: Za pozornost stojí fino-volžské *lešte ,list' > fin. lehti, gen. lehden, karel.-olon. leht'i, lud. leht', veps. leht, est. leht, gen. lehe, liv. lé $\bar{D}$,list', vedle fin. lehto ,listnatý lesík, remízek', vod. lehto ,list' , fin. lehdes ,listoví, olon. lehtes ,větev listnatého stromu', lud. lehtez, l'ehtes, list, listoví, veps. l'ehtęs ,list', est. lehes ,list, listoví, a fin. lehvä ,větev listnatého stromu'; saami (Norsko) lâs'tâ, (Lule) las̄ta, (Vefs.) rảstદ,, (Inari) los̄t ${ }^{A}$, (Ter) last, (Kildin) løst; mari (KB) laštäš, aləštäš, (U B) lâštaš, (M) lištaš (SKES 284; UEW 689). Případný baltský zdroj v podobě *lišt není vyloučen, i když chybí přímé doklady ${ }^{2}$. Substituce ${ }^{*} i>{ }^{*} e$ má analogii např. ve fin. ehkä snad', vfin. dial. ehki, est. ehk < bfin. *eški, s pravděpodobnou baltskou predlohou, kterou reprezentuje stlit. ižg(i) \& išg(i) ,aus, von, von - her' (LIUKkonen 1999, 24-25; ALEW I, 402).

3. Toch. B rīye, A ri ,město' (AdAMs 2013, 582) bývá tradičně promítáno do ob. toch. ${ }^{*} r i \bar{n} i \bar{e}<{ }^{*} u_{n}{ }_{i} H_{1}-e n-$. Rekonstrukce počáteční souhláskové skupiny se opírá jen

2 Lit. laĩ̌kas, láiškas ,stéblo, nat'; dopis, list, stránka (knihy)', lot. laiska ,das Blatt am Flachsstengel, am Getreidehalm', prus. lăiskas ,kniha' mají formálně nejblíže k sl. *lěska líska' (Toporov 1990, 37-41). Souvislost s psl. *lîsţ , list' je možná jen na kořenové úrovni. 


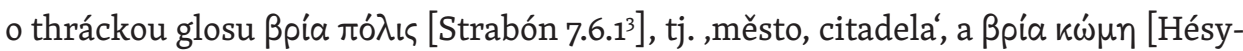
chios], tj. ,neopevněná vesnice (= lat. vīcus); zemské město, městská čtvrt", v opozici $\mathrm{k}$,opevněnému městu', pokud je odvoditelné z *ưriH ${ }_{1}-\mathrm{eH}_{a}$ - (AdAMS 2013, 582; VAN WINDEKENS 1976, 405; SMITH 1910, 43). Ř. ṕíov ,vrchol hory, předhůří nemůže souviset $\mathrm{s}$ tocharským slovem pro ,město vzhledem $\mathrm{k}$ myk. ri-jo, dovolujícímu pouze východisko *rhiion < ${ }^{*}(s)$ riiom, nikoliv ale *uriiom. Prařecké ${ }^{*}$ rhiion je slučitelné s het. šêr ,nahoře' adv., šarā ,nahoru, vzhůru' (adv.); ,nad' (postp.), klín. luv. šarri ,nad, nahoru; pro', šarra ,na (tom)', lyk. hri ,nahoru; na' (KLOEKHoRst 2008, 729). Witczak (1991, 107, pozn. 1) soudí, že thrácké $\beta$ pía je téhož původu za předpokladu vývoje *sr- > thr. (či dák.) br- (podobně jako v lat. tenebrae ,temnota' véd. támisrā,temná noc'). Oporu hledá v substrátovém ornithonymu, jež proniklo do rum. barză, bulh. dial. (N. Selo) bárzъ ,čáp', jež by mělo odrážet *srĝo-, rekonstruované na základě germ. *sturkaz ,čáp' a skt. srjayá- m. \& srjayá- f. ,brodivý pták'.

Pomiňme problematický staročínský či tibetský zdroj (sr. Luвотsкy 1998, 386: toch. > stčín., ale LUBOTSKY - STAROSTIN 2003, 264: toch. < stčín.; podrobnou diskusi viz BLAžEK - SCHWARZ 2017a, 60; 2017b, 65) a zvažme, zda není k dispozici alternativní indoevropská etymologie. $\mathrm{K}$ tomu je třeba vzít v úvahu, že v obou tocharských jazycích platí hláskový zákon o zjednodušení souhláskové skupiny

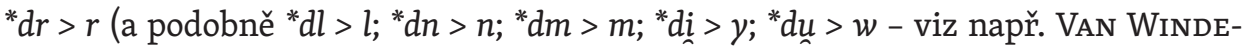
KENS 1976, 82, §241). Toto pravidlo otevírá možnost identifikovat v tocharském slově ,město hypotetický protějšek r. derévnja ,vesnice.. Ruské slovo bývá odvozováno z praformy ${ }^{*} d$ brvbnja ${ }^{*}$,orná půda $\sim$ lit. dirvà ,pole $\left(\right.$ VASMER I, 341) < ${ }^{*} d r H u^{\circ}$, nebo z dérevo ,dřevo' (MikLosich 1886, 42-43). Brückner (1925, 1-2) explicitně odmítl jakékoliv spojení s lit. dirvà ,polé. Miklosichova ,dřevěná etymologie může být navíc podpořena existencí ukrajinského slova derévnja ,les', které má též význam ,dřevěný dům' (TRUBAČEv, ESSJ 4, 214). V takovém př́padě lze promítnout východoslovanské slovo ,vesnice do praslovanského východiska *dervınja. Vzhledem k různým derivačním sufixům si tocharská a slovanská forma neodpovídají sice přesně, ale sémantická motivace ,sestávající z dřevěných domů i výchozí kořen *dreu-/*deru,strom, dřevo" jsou identické. Východiskem tocharských forem by měla být forma *dreuio-4, adjektivum utvořené sufixem *-ino- od hypotetického genitivu *dreus,

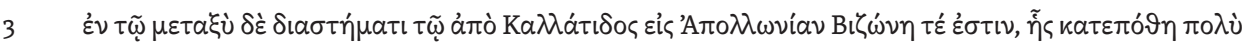

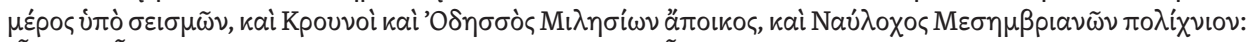

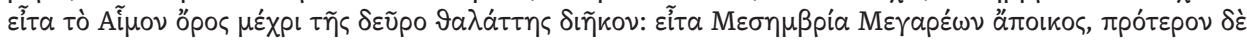

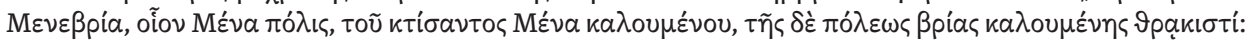

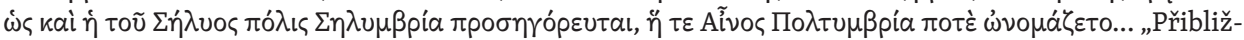
ně uprostřed mezi Kallatis a Apollonií se nachází Bizone, kterou z velké části spolklo zemětřesení; Krunoi (= dnes Balčik); Odessos (= Varna), kolonie Milétských; a Naulochos, malé město mesembrijských. Dále následuje pohoří Haimos (= Balkánské pohoří, též Stara Planina dnes), táhnoucí se k moři v této části; poté Mesembria (= Nesebăr), kolonie Megarenských, dřive zvaná Menabria či město Meny, \{kde\} Menas je jméno zakladatele, a bria značí v thráčtině „město“. Tudíž město Selys se nazývá Selybria a Ainos kdysi nesl jméno Poltyobria." (viz Hamilton-Falconer, eds. 1903-1906).

4 Doloženo v skt. adj. dravya-, vztahující se ke stromu' (MW 501). Sr. též lit. drẽvè, dutina v kmeni stro- 
jenž implikuje nominativ *doru proterodynamického paradigmatu, známého např. $\mathrm{z}$ véd. dấru, gen. drós ,dřevo'. Proterodynamické paradigma nom. *doru vs. gen. *dreus vysvětluje též ztrátu *d- v toch. AB or, pl. B ārwa ,strom při aplikaci pravidla *dr- > r-, nejprve realizovaného $\mathrm{v}$ gen. sg., a poté generalizovaného $\mathrm{v}$ celém paradigmatu (sr. Hilmarsson 1984, 112, jenž ale předpokládal gen. sg. *drous). Vývoj sekvence *-euio- byl též zřejmě regulérní, jestliže vedl $\mathrm{k}^{*}$-eiijo- ${ }^{-5}{ }^{*}{ }^{*}$-iio- ${ }^{6}>$ toch. $\mathrm{B}$-ĭye (viz BLAŽEK 2016, 225-27). Za pozornost stojí shodná sémantická motivace vedoucí k pojmenování ,městá, resp. ,vesnice. Obydlí vystavěná ze dřeva se nesporně liší od trvanlivějších sídel zbudovaných převážně z kamene na jedné straně i primitivnějších př́íbytků v jeskyních a zemljankách.

\section{Zkratky}

Av. avestský, bfin. baltsko-finský, bhs. buddhistický hybridní sanskrt, br. běloruský, bulh. bulharský, č. český, čín. čínský, d- dolno-, dák. dácký, est. estonský, fin. finský, germ. germánský, gót. gótský, h- horno-, het. hetitský, karel. karelský, kaš. kašubský, lat. latinský, lit. litevský, liv. livonský, lot. lotyšský, lud. ludikovský, luž. lužicko-srbský, mak. makedonský, niz. nizozemský, olon. olenecký, plb. polabský, pol. polský, prus. pruský, r. ruský, rum. rumunský, ř. řecký, sev. severský, sch. srbochorvatský, skt. sanskrt, sl. slovanský, slk. slovenský, sln. slovinský, st- staro-, střr- středo-, stsl. staroslověnský, thr. thrácký, toch. tocharský, ukr. ukrajinský, v- východo-, véd. védský, velš. velšský, veps. vepský, vod. vodský. Zkratky staroindických literárních památek jsou všeobecně používány podle vzoru MW.

\section{REFERENCES}

Adams, Douglas Q. 1988. Tocharian Historical Phonology and Morphology. New Haven: American Oriental Society. American Oriental Series, Vol. 71. .

AdAms, Douglas Q. 2013. A Dictionary of Tocharian B (Revised and Greatly Enlarged), Vol. 1-2. Amsterdam-New York: Rodopi.

ALEW = Altlitauisches etymologisches Wörterbuch, Band I (A-M), unter Leitung von Wolfgang Hock und der Mitarbeit von Elvira-Jūlia Bukevičiūte und Christiane Schiller, bearbeitet von Rainer Fecht, Anna Helene Feulner, Eugen Hill und Dagmar S. Wodtko. Hamburg: Baar 2015.

BLAŽEK, Václav. 1991. Slavic-Tocharian Isoglosses I. Sl. *kъpъ : Toch. *kwip- "shame”; II. Sl. *člnъ : Toch. *kolmo- "ship". Tocharian and Indo-European Studies 5, 123-128; 129-133 (přetisk - BLAŽEK 2011, 10-18).

mu'< *dreuiiiā. Pro tvar *dreuio-/*drouio- Charpentier $(1906,25)$ dokonce předpokládal význam ,dům.

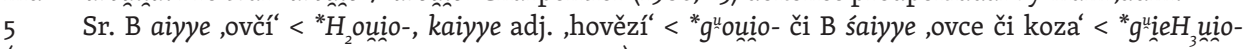
(ADAMS 2013, 110, 214, 695; VAN WindeKens 1976, 95).

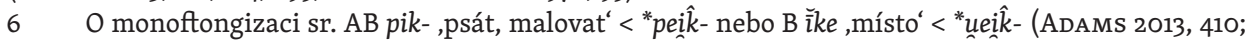
VAN WiNDEKENS 1976, 30). 
BLAžEK, Václav. 1994. Sl. *č̋lnъ „člun“ a toch. *kolmo- „lod'“ (k terminologii pojmenování plavidel v severoindoevropském areálu). Slavia 62, 489-492.

BLAŽEK, Václav. 1995a. Slavic-Tocharian Isoglosses. Linguistica Baltica 4, 233-238 (přetisk BLAŽEK 2011, 19-24).

BLAŽEK, Václav. 1995b. Př́nos Václava Machka pro indoevropskou etymologii. Slavia 63, 499501.

BLAŽEK, Václav. 1997. Praslav. *kъpъ 'vulva' tox. *kwip- 'styd' - specifičeskaja slavjansko-toxarskaja izoglossa? Balto-slavjanskie issledovanija, 226-229.

BLAŽEK, Václav. 1999. Alimenta Tocharica (1-3). Tocharian and Indo-European Studies 8, 79-84 (přetisk - BLAŽEK 2011, 40-45).

BLAŽEK, Václav. 2003. Slavic-Tocharian Isoglosses IV. Tocharian and Indo-European Studies 10, 11-13 (přetisk - BLAžEK 2011, 60-62).

BLAŽEK, Václav. 2011. Tocharian Studies. Ed. Schwarz, Michal. Brno: Masaryk University.

BLAŽEK, Václav. 2013. A Balto-Slavic key to etymology of Tocharian B twār. Baltistica 48(1), 69-73.

BLAžEK, Václav. 2016. (Review of) Adams, Douglas Q.: A Dictionary of Tocharian B. Revised and Greatly Enlarged, Vol. I-II \{Amsterdam-New York: Rodopi 2013\}. Journal of Indo-European Studies 44(1-2), 218-243.

BLAŽEk, Václav - SchwARz, Michal. 2011. Tocharian AB kwär- 'to grow old'. Tocharian and Indo-European Studies 12, 57-62 (přetisk - Blažek 2011, 78-82).

BLAžEK, Václav - SchwARz, Michal. 2017a. Early Indo-Europeans in Central Asia and China. Cultural Relations as reflected in Language. Innsbruck: Innsbrucker Beiträge zur Kulturwissenschaft, Neue Folge, Band 13.

BLAžEK, Václav - SchwARZ, Michal. 2017b. Raní Indoevropané v Centrální Asii a Číně. Kulturní vztahy v zrcadle jazyka. Praha: Nakladatelství Lidové noviny.

Bonfate, Giuliano. 1979. Un'isoglossa Balto-Slavo-Tocharia. Rendiconti delle sedute dell'Accademia Nazionale dei Lincei 34(3-4), 81-84.

Bonfate, Giuliano. 1984. I. Il femminile inanimato in tocario e in slavo. II. Un caso chiaro ed uno misterioso in tocario. Acta Iranica 23, 61-66.

BRÜCKNER, Alexander. 1925. Waldnamen und Verwandtens. Archiv für slavische Philologie 39, 1-12.

Charpentier, Jarl. 1906. Indische Wortforschung. Le Monde Oriental 1, 17-42. [cit. 25. 6. 2018] Dostupné z: https://archive.org/details/lemondeorientalo1upps

Čop, Bojan. 1959-1960. Etyma Balto-Slavica IV. Slavistična revija 12, 170-193.

DTA = Dictionary and Thesaurus of Tocharian A, Vol. I: A-J. Comp. Gerd CARLIng in collaboration with Georges-Jean PinAUlt and Werner WinTER. Wiesbaden: Harrassowitz 2009.

EIEC = Encyclopedia of Indo-European Culture. Ed. James P. MALLORY - Douglas Q. AdAMs. London-Chicago: Fitzroy Dearborn Publishers 1997.

ESJS = Etymologický slovník jazyka staroslověnského. Ed. Eva Havlová et alii. Praha: Academia / Brno: Tribun EU 1989f.

ESSJ = Ėtimologičeskij slovaŕ slavjanskix jazykov. Ed. Oleg N. TRUBAČEv et alii. Moskva: Nauka $1974 f$.

Fortescue, Michael. 2005. Comparative Chukotko-Kamchatkan Dictionary. Berlin - New York: Mouton de Gruyter. 
Georgiev, Vladimir I. 1958. Balto-slavjanskij i toxarskij jazyki. Voprosy jazykoznanija.

Georgiev, Vladimir I. 1981. Tocharian and Balto-Slavic. In: Georgiev, Vladimir I., ed. Introduction to the History of the Indo-European Languages. Sofia: Bulgarian Academy of Sciences, 281-297.

GPC Geiriadur Prifysgol Cymru. A Dictionary of the Welsh Language. Centre for Advanced Welsh - Celtic Studies. [cit. 25. 6. 2018] Dostupné z: http://welsh-dictionary.ac.uk/gpc/ gpc.html

Hamilton, Hans Claude - Falconer, William, eds. 1903-1906. The Geography of Strabo. Literally translated, with notes, in three volumes. London: George Bell \& Sons.

HilmaRsson, Jörundur. 1984. Notes on East Tocharian ort 'friend(?)' etc., and the question of u-umlaut of Tocharian a. Münchener Studien zur Sprachwissenschaft 43, 107-121.

Hilmarsson, Jörundur. 1996. Materials for a Tocharian Historical and Etymological Dictionary. Reykjavík: Málvísindastofnun Háskóla Íslands. Tocharian and Indo-European Studies, Supplementary Series, Vol. 5 .

IvANov, Vjačeslav V. 1958. Toxarskaja parallel' k slavjanskim umeńšitel'nym formam. In: Slavjanskaja filologija. IV meždunarodnyj sjezd slavistov - sbornik statej II. Moskva: Izdatel'stvo AN SSSR, 58-63 (přetisk - IvANov 2008, 574-579).

IvANov, Vjačeslav V. 1988. Balto-slavjano-toxarskie izoglossy. Balto-slavjanskie issledovanija 1986, 45-60.

IvANov, Vjačeslav V. 1998. Kontakty slavjanskogo s toxarskim. In: TrubačEv, Oleg N., ed. XII Meždunarodnyj sjezd slavistov $v$ Krakove - Doklady russkix učenyx. Moskva: Nauka, 325-334.

IvANov, Vjačeslav V. 2002. Ešče raz o slavjano-toxarskix izoglossax. In: NikolAEvA, Tatjana M., ed. Slavjanskaja jazykovaja i ètnojazykovaja sistema $v$ kontakte s neslavjanskim okruženiem. Moskva: Jazyki slavjanskix kul'tur, 52-54 (přetisk - IvANov 2008, 580-582).

Ivanov, Vjačeslav V. 2008. Trudy po ėtimologii indoevropejskix i drevneperedneaziatskix jazykov, Tom 2. Moskva: Jazyki slavjanskoj kul'tury.

KLOEkHORST, Alwin. 2008. Etymological Dictionary of the Hittite Inherited Lexicon. LeidenBoston: Brill.

KortlandT, Frederik. 1983. Demonstrative Pronouns in Balto-Slavic, Armenian, and Tocharian. In: Dutch Contributions to the Ninth International Congress of Slavists (Kiev, Sept 1983). Amsterdam: Studies in Slavic and General Linguistics 3, 32-35.

Kroonen, Guus. 2013. Etymological Dictionary of Proto-Germanic. Leiden-Boston: Brill.

LEHR-SpєAWIŃSKI, Tadeusz. 1957-1958. Zur Frage nach der Stellung des Slavischen und des Tocharischen innerhalb der indoeuropäischen Sprachenwelt. Wiener Slavistisches Jahrbuch 6, 138-146.

LiukKonen, Kari. 1999. Baltisches im Finnischen. Helsinki: Finnisch-Ugrische Gesellschaft. Mémoires de la Société Finno-Ougrienne, Vol. 235.

Luвотsкy, Alexander. 1998. Tocharian loan words in Old Chinese: chariots, chariot gear, and town building. In: MAIR, Victor A., ed. The Bronze Age and Early Iron Age peoples of Central Asia. Washington D. C.: Institute for the Study of Man, 379-390.

Lubotsky, Alexander - Starostin, Sergei. 2003. Turkic and Chinese loan words in Tocharian. In: BAuer, Brigitte L. M. - PinAult, Georges-Jean, eds. Language in Time and Space. A Festschrift for Werner Winter on the Occasion of his 8oth Birthday. Berlin-New York: Mouton de Gruyter, 257-269. 
Malzahn, Melanie. 2016. Review of Adams 2013. Journal of the American Oriental Society 136(3), 661-663.

MikLosich, Franz. 1886. Etymologisches Wörterbuch der slavischen Sprachen. Wien: Braumüller.

Miliuté-ChomičenkienÉ, Aleta. 1990. Baltų-slavų-tocharų leksikos gretybès ('Gyvūnų pavadinimų' leksinè-semantinè grupè) \{„Etymologické paralely v baltštině, slovanštině a tocharštině ve 'názvech zvířat a jejich částí těla'"\}. Baltistica 26(2), 135-143.

MW = Monier-Williams, Monier. 1899[1993]. A Sanskrit-English Dictionary. Delhi: Motilal Banarsidass. [cit. 25. 6. 2018] Dostupné z: http://www.sanskrit-lexicon.uni-koeln.de/cgibin/tamil/recherche

Pinault, Georges-Jean. 2008. Chrestomathie tokharienne. Textes et grammaire. Leuven-Paris: Peeters.

Pokorny, Julius. 1959. Indogermanisches etymologisches Wörterbuch. Bern-München: Francke. SARADŽEvA, Ludviga Alekseevna. 1982. An Armeno-Slavo-Tocharian Innovation. Annual of Armenian Linguistics 3, 47-52.

SKES = ToIVONEN, Y. H. et alii. 1955f. Suomen kielen etymologinen sanakirja, I-VII. Helsinki: Lexica Societatis Fenno-Ugricae XII.1-7.

SмIтн, E. 1910. „Tocharisch“, die neuentdeckte indogermanische Sprache Mittelasiens. Christiania: Vid. Selsk. Skriften, II. Hist-fil. Kl., Nr. 2.

Toporov, Vladimir N. 1963. Toxarskaja ètimologija za dvadcat' let. Ėtimologija 1963, 236-249. Toporov, Vladimir N. 1990. Prusskij jazyk 5 (laydis - lut-). Moskva: Nauka.

UEW = Uralisches etymologisches Wörterbuch, von Károly Rédei et alii. Budapest: Akadémiai Kiadó 1986-88.

VALČÁKovÁ, Pavla - BlAžEk, Václav. 1997. Psl. *kols. Sborník prací filozofické fakulty brněnské university, A 45, 27-30.

VAN Windekens, Albert J. 1971. Une correspondence lexicale entre le tokharien et le balto-slave. Indogermanische Forschungen 76, 54-58.

VAN WINDEKENS, Albert J. 1976. Le tokharien confronté avec les autres langues indo-européennes, I: La phonétique et le vocabulaire. Louvain: Centre International de Dialectologie Générale.

VASMER, Max. 1986-88. Étimologičeskij slovaŕ russkogo jazyka, I-IV, translated in Russian by Oleg N. Trubačev. Moskva: Progress.

Witczak, Krzysztof T. 1991a. Indo-European *srC in Germanic. Historische Sprachforschung 104, 106-107.

WitczaK, Krzysztof T. 1999. Review of Hilmarsson 1996. Studia Etymologica Cracoviensia 5, 202-205.

Poděkování: Článek vznikl pod záštitou Specifického výzkumu, č. 2817. Poděkování patří též dvěma anonymním recenzentům, jejichž užitečné komentáře byly promítnuty do finální verze př́spěvku. 


\section{Václav Blažek}

Department of Linguistics and Baltic Studies

Faculty of Arts, Masaryk University

Arna Nováka 1, 602 oo Brno

Czech Republic

blazek@phil.muni.cz 
